\title{
Ampulla of Vater Carcinoma
}

National Cancer Institute

\section{Source}

National Cancer Institute. Ampulla of Vater Carcinoma. NCI Thesaurus. Code C3908.

A carcinoma arising from the ampulla of Vater. The vast majority of cases are adenocarcinomas. Signs and symptoms include jaundice, abdominal pain, anorexia, nausea, vomiting, and weight loss. 